\title{
Guidelines for nursing care: an effective tool for the promotion of health in puerperium
}

\author{
Diretriz para assistência de enfermagem: ferramenta eficaz para a promoção da saúde no \\ puerpério
}

\author{
Directrices para la atención de enfermería: herramienta eficaz para promoción de la salud \\ en el postparto
}

\author{
Ana Beatriz Querino Souza ${ }^{1}$ Betânia Maria Fernandes ${ }^{2}$
}

The aim of the study was at accessing the feasibility of a guideline of nursing care in the puerperium in primary health care. It is a quasi-experimental research conducted with 168 postpartum women in Juiz de Fora, MG, Brazil, from November 2011 to May 2012. In the intervention group, women were subjected to the guidelines with five puerperal appointments and the control group women were not exposed to the guideline. The results were significant for exclusive breastfeeding, with $42.9 \%$ in the intervention group and $25.4 \%$ in the control $(\mathrm{p}=0.002)$; Panicolaou's test with $85 \%$ in the intervention group and $63.2 \%$ in the control ( $p=0.002)$; use of ferrous sulfate $26.2 \%$ in the intervention group and $18.3 \%$ in control ( $<<0.001)$. A better vaccination coverage in the intervention group was also observed. The significant results in most variables show the feasibility of the guideline of nursing care in the puerperium.

Descriptors: Nursing Care; Postpartum Period; Primary Health Care.

Objetivou-se verificar a viabilidade de uma diretriz de assistência de enfermagem no puerpério na atenção primária à saúde. Pesquisa quase-experimental, desenvolvida com 168 puérperas no município de Juiz de Fora, MG, Brasil, de novembro de 2011 a maio de 2012. No grupo de intervenção, as mulheres foram submetidas à diretriz com cinco consultas puerperais, e as do grupo controle não foram expostas à diretriz. Os resultados foram significativos para o aleitamento materno exclusivo, com 42,9\%, no grupo de intervenção, e 25,4\%, no controle ( $\mathrm{p}=0,002)$; exame de Panicolaou com $85 \%$, no grupo

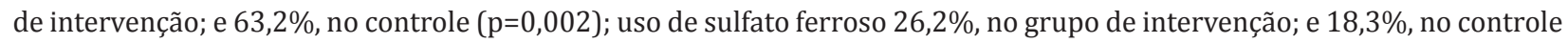
$(\mathrm{p}<0,001)$. Também foi evidenciada melhor cobertura vacinal no grupo de intervenção. Os resultados significativos, na maioria das variáveis, evidenciaram a viabilidade da diretriz de assistência de enfermagem no puerpério.

Descritores: Cuidados de Enfermagem; Puerpério; Atenção Primária à Saúde.

El objetivo fue evaluar la viabilidad de una directriz de atención de enfermería en el posparto en la atención primaria de salud. Investigación cuasi-experimental, con 168 puérperas, en ciudad de Juiz de Fora, MG, Brasil, de noviembre/2011 a mayo/2012. En el grupo de intervención, las mujeres fueron sometidas a la directriz con cinco consultas puerperales, y las de grupo control, no fueron expuestas a la directriz. Los resultados fueron significativos para lactancia materna exclusiva, con $42,9 \%$, en el grupo de intervención y 25,4\%, en el control ( $p=0,002)$; examen Panicolaou, $85 \%$, en el grupo de intervención; y $63,2 \%$, en el control ( $p=0,002$ ); uso de sulfato ferroso, 26,2\%, en el grupo de intervención; y 18,3\%, en el control ( $p<0,001)$. También hubo mejor cobertura vacunal en el grupo de intervención. Los resultados significativos, en la mayoría de las variables, señalaron viabilidad de la directriz de atención de enfermería en el posparto.

Descriptores: Atención de Enfermería; Período de Postparto; Atención Primaria de Salud.

\footnotetext{
${ }^{1}$ Secretaria de Saúde de Juiz de Fora, Juiz de Fora, MG. Brazil.

${ }^{2}$ Universidade Federal de Juiz de Fora. Juiz de Fora, MG, Brazil.

Corresponding author: Ana Beatriz Querino Souza

Rua Dr. OldemirMazocoli, 310, Bosque dos Pinheiros II, CEP: 36062-055. Juiz de Fora, MG, Brazil. E-mail: bistetriz@hotmail.com
} 


\section{Introduction}

The post-partum, also known as puerperium, is the period after delivery in which the woman experiences changes and physical and psychic adaptations, aiming at the return of the pre-gravidic condition. Although it is defined as an interval of six weeks, it goes from the birth of the newborn until the physiological normalization, so the length of time can be variable. It can be classified in three phases: immediate puerperium, which goes from birth to the $10^{\text {th }}$ day of post-partum; late puerperium, which is from the $11^{\text {th }}$ to the $42^{\text {nd }}$ day and remote puerperium, which is from the $43^{\text {rd }}$ day to one year of postpartum $^{(1-2)}$.

Although most of the alterations in post-partum are physiological, the puerperas experience changes, fears, challenges, anxiety and situations of risk which may negatively affect the work of the binomial motherchild. Adding to those there are risks of real problems already settled, which show the need of work of the nurse through an assistance closer to the woman ${ }^{(1-3)}$.

Intercurrences in the puerperal period represent a good part of the situations of maternal and neo-natal morbidity and mortality. The main causes of maternal death in Brazil are the hemorrhagic syndromes, arterial hypertension, pregnancies resulting in abortion and puerperal infections. Besides the hemorrhagic syndromes and puerperal infections, other intercurrences can negatively affect the health of the woman and the baby in this period, such as the early weaning, post-partum depression and a new pregnancy in the puerperal period ${ }^{(4-5)}$.

Although puerperium can be a period of greater vulnerability and number of intercurrences if compared to other stages of the gravidic puerperal cycle, it is the phase in which the woman is not unassisted by the health team ${ }^{(1)}$. In this period the women are more vulnerable and sensitive to receive influences of the health professionals ${ }^{(6)}$. Facing this fact, the health professionals should use the opportunity of the puerperal period to provide actions for the promotion of health and the prevention of diseases. One of the parameters established by the Health Department for the quality of the assistance to post-partum is the assistance to the woman and to the newborn in the immediate and late puerperium. The recommended protocol of puerperal assistance consists in at least two appointments: a home visit until the $7^{\text {th }}$ day after delivery and a puerperal appointment on the $42^{\text {nd }} d a y^{(5)}$.

Despite the actions proposed by the Health Department, the puerperal attention is not yet consolidated in the services of health in Brazil. The last national research of demography and health of the child and the woman published in 2009 highlighted that $60.8 \%$ of the women did not have any appointment in puerperium. Many women do not return to the post-partum assistance and, in most cases, an active search of those puerperas is not made by the health professionals. It is common for those women to return exclusively to follow the growth, development and immunization of the baby ${ }^{(5,3)}$

The puerperium has been assisted irregularly, whose care in most of the cases is directed to the newborn, with insufficient attention to the main protagonist of this period, exposed to transformations and physical and psychosocial risks ${ }^{(7)}$.

Facing the universe of actions to be taken in the puerperium and the need of those actions to be followed continuously, we believe it is necessary to have a guideline with a higher number of appointments and actions.

The object of study of this investigation is outlined as the nursing assistance in puerperium through a guideline, which is aimed at assisting the puerperas until the $3^{\text {rd }}$ month after delivery by the nurses of the units of primary attention to health with the family health strategy. The objectives of the study were to verify the viability of application of a guideline of nursing assistance in the puerperium in the primary attention to health and to identify the behavior of the unleashing variables (maternal breastfeeding, use of contraceptive method, use of 
ferrous sulfate, vaccination schedule, making of pap smear) in a group of puerperas that was assisted by the proposed nursing guideline compared to another group of women which had not being assisted by such guideline.

\section{Method}

The outlining of the study was the quasiexperimental type. In this outlining, the researcher directly or indirectly makes intervention, however, there is no random allocation of the participants to the groups which will suffer the intervention ${ }^{(8)}$.

The study was developed in the county of Juiz de Fora, MG, Brazil, in 15 units of primary health care which act with the family health strategy. The county has 88 family health teams which assist an average of 3,000 inhabitants per team, which is equivalent to coverage of $56 \%$.

The population of the study has a total of 168 puerperas, independently of number of children and the kind of delivery they had, divided into intervention group and control group. The intervention group had 42 puerperas assisted to the proposed guideline and the control group had 126 puerperas who received another kind of assistance. The sample of the study was calculated through the monthly average of births through the System of Living Newborn and consequently, through the puerperas for the areas with Family Health Strategy (coverage by 88 teams) was 162 . Of the 88 nurses of the family health teams of the county, only 21 of the health professionals accepted to contribute to the study. So, the monthly average of puerperas for those nurses was 38 .

The data collection was made in a period of seven months, from November 2011 to May 2012, with an estimate of 266 puerperas for that period. Considering a level of significance of $5 \%$ and a power of test of $80 \%$, the population of the study would be 156 puerperas. In order to work with a safety margin due to possible losses, the final population was 168 puerperas, of those 42 allocated in the intervention group and 126 in the control group, adopting a relation of one to three.

In the present research, the control group and the intervention group were formed by convenience, once the puerperas who participated in the study were resident in the area of coverage of the unit of primary attention to health, in which the nurses were willing to participate in the research applying the guideline. The blinding of the groups was not possible either, once there was the purpose of applying a differentiated guideline, and both the nurse as well as the puerpera were informed of the proposal of the study. The puerperas received information on the number of appointments they would be submitted to during the first three months of puerperum.

The criteria of inclusion of the women of the intervention group were: puerperas who were in the first ten days of puerperium and had missed none of the five appointments. In the control group, puerperas from 90 days until 120 days of puerperium were included. This period was defined in order to collect the maximum amount of information facing the possible interventions of the teams of the units of primary attentions to health to the puerperas. This period was also established because the last assistance to the intervention group happened on the $90^{\text {th }}$ day and consequently the data collection made by the researcher would always occur between 90 to 120 days, avoiding that the data collection would be made at different times in the groups and bias in the study.

Besides these criteria, the puerperas who attended the following conditions were included in the two groups: being older than 18 years, having made the low risk or habitual risk pre-natal examination, having retuned home with the baby after delivery, that is, the baby was not hospitalized, was not sent for adoption, did not die and accepted to participate in the study.

The criteria of exclusion were as follows: being younger than 18, had been assisted in the pre-natal examination of high risk, did not return home with the baby, did not accept to participate in the study, 
missed some of the five appointment and had more than 10 days from post-partum when they belonged to the intervention group and were not in the period between 90 and 120 days of puerperium when they belonged to the control group.

The intervention group was submitted to five nursing appointment made by the nurses of the units of primary attention to health, and one appointment was in the immediate puerperium with seven to ten days, two appointments in the late puerperium and the first appointment from 25 to 30 days and the second one with 42 days, and, finally, two appointments in the remote puerperium with 60 and 90 days. The nurses went through all the stages of nursing appointments: anamnesis, general and specific physical examination, diagnosis and nursing prescription.

The women for this group were recruited in the third semester of the pre-natal, when they had the control at the unit of primary health care or in the visit of puerperium after the birth of the baby. During the appointments the nurses made use of a form elaborated for the research which we called clinical register of puerperium, which, besides directing the appointments, was also the instrument of register and data collection of the intervention group. After the last appointment, the researcher collected the data in the mentioned instrument at the health unit.

The nurses who made the nursing appointments with the intervention groups were trained by the researcher in a meeting of eight hours in April, 2011 after the authorization of the health department. In this meeting the nursing assistance in post-partum was discussed through the form elaborated in order to standardize the collection. Later on, the form was tested by three of the nurses, who did not participate in the study for $11 \%$ of the total of the sample of the intervention group (five puerperas) from June to September, 2011. After the test, the necessary adjustments in the form were made and the field work started.

For the control group, the only method adopted was a home visit made by the researcher and assistants of research for the data collection after agreement and signing the informed consent form, afterwards the data collection started. The purpose was to know the quantity and quality of possible appointments made in the puerperium. It was expected to identify, in this visit, whether the puerpera had gone to at least the two appointments with the health team, preconized by the health department and the county protocol: a nurse home visit or an appointment at the unit of primary health care or at the venue where delivery occurred until the $10^{\text {th }}$ day of post-partum and another appointment at the unit of primary attention between 30 to 42 days of puerperium.

The independent variable of the study was the nursing assistance in puerperium through a guideline with five nursing appointments. The dependent variables or primary unleashing evaluated were related to some common intercurrences in this period and behaviors, as follows: exclusive maternal breastfeeding, use of adequate contraceptive method, use of ferrous sulfate for 90 days of puerperium, immunization with these vaccines: anti-tetanic, rubella and hepatitis B and Papanicolaou's test.

The intervening variables were: maternal age, ethnic group, marital status, schooling, parity, number of pre-natal appointments, type of delivery and maternal breastfeeding in the first hour of living.

The instrument for data collection of the control group was a structured interview with information of identification, social economic and cultural data, prenatal and puerperium, prioritizing the unleashing variables. In the intervention group, a questionnaire for data collection of puerperal register was used.

For the statistical analysis, the Statistical Package for Social Sciences for Windows version 14 was used. For the analysis of the qualitative variables, which were the majority in this study, the absolute and percentage frequencies were calculated. The comparison between the groups of study and control was made through the chi-square test considering the value of $\mathrm{p}<0.05$. Facing a positive association, there was the measure of the strength of the association 
through the Odds Ratio.

The present investigation followed the recommendation of the Brazilian legislation according to Resolution 466/2012 of the National Health Counsel for the research involving human beings, having been submitted to the Committee of Ethics in Research of the Universidade Federal de Juiz de Fora and approved by ordinance no. 307/2010 as of February $17^{\text {th }}, 2011$.

\section{Results}

The data obtained in the intervention and control groups are described in Tables. At first, the data of characterization of the puerperas as to the demographic variables will be presented (Table 1).

Table 1 - Distribution of the puerperas according to the demographic variables: age, ethnic group, marital status, schooling and paid work

\begin{tabular}{|c|c|c|c|}
\hline \multirow{2}{*}{$\begin{array}{l}\text { Demographic } \\
\text { variables }\end{array}$} & $\begin{array}{c}\text { Intervention } \\
\text { Group }\end{array}$ & $\begin{array}{l}\text { Control } \\
\text { Group }\end{array}$ & \multirow[t]{2}{*}{$\begin{array}{c}\mathrm{p} \\
\text { value }\end{array}$} \\
\hline & n (\%) & n (\%) & \\
\hline Age (years) A (sd)* & $27,33(5.7)$ & $26,63(5.9)$ & 0.307 \\
\hline 19 to 29 & 29 (69.1) & 89 (70.7) & \\
\hline 30 to 45 & $13(30.9)$ & 37 (29.3) & \\
\hline Ethnic group & & & 0.590 \\
\hline White & $18(42.9)$ & $60(47.6)$ & \\
\hline Dark-skinned & $15(35.7)$ & $33(26.2)$ & \\
\hline Black & $08(19.0)$ & $32(25.4)$ & \\
\hline Yellow & $01(0.8)$ & $01(2.4)$ & \\
\hline Marital Status & & & 0.292 \\
\hline With a partner & $26(61.9)$ & $89(70.6)$ & \\
\hline Without a partner & $16(38.1)$ & 37 (29.4) & \\
\hline Schooling & & & 0.471 \\
\hline $\begin{array}{l}\text { Incomplete high } \\
\text { school or less }\end{array}$ & $22(52.4)$ & 74 (58.7) & \\
\hline $\begin{array}{l}\text { Complete high } \\
\text { school or more }\end{array}$ & $20(47.6)$ & $52(41.3)$ & \\
\hline Paid work & & & 0.054 \\
\hline Yes & $23(34.8)$ & $55(43.7)$ & \\
\hline No & $16(38.1)$ & $69(54.8)$ & \\
\hline Not informed & $3(7.1)$ & $02(1.6)$ & \\
\hline
\end{tabular}

The obstetric profile of the puerperas is described as follows, approaching parity, number of pre-natal appointments, intercurrence in the prenatal, type of delivery, occurrence of episiotomy and maternal breastfeeding in the first hour of life (Table 2).

Table 2 - Distribution of the puerperas according to obstetric variables

\begin{tabular}{|c|c|c|c|}
\hline \multirow[t]{2}{*}{ Obstetric variables } & $\begin{array}{c}\text { Intervention } \\
\text { Group }\end{array}$ & $\begin{array}{c}\text { Control } \\
\text { Group }\end{array}$ & \multirow[t]{2}{*}{$\begin{array}{c}p \\
\text { value }\end{array}$} \\
\hline & n (\%) & n (\%) & \\
\hline \multicolumn{3}{|l|}{ Parity } & 0.048 \\
\hline Primipera & $25(59.5)$ & $50(39.7)$ & \\
\hline 2 or more children & $17(40.5)$ & $76(60.3)$ & \\
\hline \multicolumn{3}{|c|}{ Number of pre-natal appointment } & 0.126 \\
\hline 1 to 3 & $1(2.4)$ & $03(2.4)$ & \\
\hline 4 to 6 & $16(38.1)$ & $28(22.2)$ & \\
\hline$\geq 7$ & $25(59.5)$ & $95(75.4)$ & \\
\hline \multicolumn{3}{|c|}{ Intercurrences in the pre-natal } & 0.531 \\
\hline Yes & $25(59.5)$ & $68(54.0)$ & \\
\hline No & $17(40.5)$ & $58(46.0)$ & \\
\hline \multicolumn{3}{|l|}{ Types of delivery } & 0.674 \\
\hline Vaginal & $19(45.2)$ & $64(50.8)$ & \\
\hline Cesarean & $22(52.40)$ & $61(48.4)$ & \\
\hline Forceps & $01(2.4)$ & $01(0.8)$ & \\
\hline \multicolumn{3}{|l|}{ Episiotomy } & 0.631 \\
\hline Yes & $15(79)$ & $42(65.6)$ & \\
\hline No & $04(21)$ & $22(34.4)$ & \\
\hline \multicolumn{3}{|c|}{ Breastfeeding in the first hour of life } & 095 \\
\hline Yes & $32(76.2)$ & $73(57.9)$ & \\
\hline No & $10(23.8)$ & $53(42.1)$ & \\
\hline
\end{tabular}

Some variables of the study are considered intervenient, that is, the difference between these and the groups of study can cause bias and interfere in the results. These variables are: maternal age, ethnic group, marital status, schooling, number of pre-natal appointments, parity, type of delivery and maternal breastfeeding in the first hour of life. The ideal goal would be to confirm the similarity in the groups of the study, which was made through the chi-square test $(\mathrm{p}>0.05)$.

The only variable which presented a significant difference between the groups was parity with $p$ value $=0.048$. All the other intervenient variables were similar comparing the groups ( $\mathrm{p}$ value $>0.05$ )

The comparison of the unleashing variables in the intervention and control groups will be presented in (Table 3). Significant statistics in the 
group of puerperas assisted through the guideline proposed regarding the ones who were not assisted were observed for the following variables: exclusive maternal breastfeeding, Papanicolaou's test, and immunization through anti-tetanic, rubella and hepatitis B vaccines and the use of ferrous sulfate for 90 days. There was no significant result for the use of contraceptive methods.

Table 3 - Comparison of the intervention group with the control group as to the outcome variables

\begin{tabular}{|c|c|c|c|c|}
\hline \multirow{2}{*}{$\begin{array}{l}\text { Outcome } \\
\text { variables }\end{array}$} & $\begin{array}{l}\text { Intervention } \\
\text { Group }\end{array}$ & $\begin{array}{l}\text { Control } \\
\text { Group }\end{array}$ & \multirow[t]{2}{*}{$\underset{\text { value }}{\mathbf{p}}$} & \multirow[t]{2}{*}{$O D^{(a)}$} \\
\hline & $n(\%)$ & $\mathbf{n}(\%)$ & & \\
\hline \multicolumn{2}{|l|}{ Breastfeeding } & & 0,020 & \\
\hline $\begin{array}{l}\text { Exclusive } \\
\text { breastfeeding }\end{array}$ & $18(42.9)$ & $32(25.4)$ & & 4.13 \\
\hline $\begin{array}{l}\text { Non exclusive } \\
\text { breastfeeding }\end{array}$ & $18(42.9)$ & $50(39.7)$ & & 2.64 \\
\hline $\begin{array}{l}\text { No breast- } \\
\text { feeding }\end{array}$ & $6(14.2)$ & $44(34.9)$ & & $1^{(\mathrm{b})}$ \\
\hline \multicolumn{2}{|c|}{ Contraceptive method } & & 0,430 & \\
\hline $\begin{array}{l}\text { Did not use } \\
\text { methods }\end{array}$ & $2(4.8)$ & $15(12.0)$ & & \\
\hline $\begin{array}{l}\text { Use of ade- } \\
\text { quate method }\end{array}$ & $32(80.0)$ & $90(81.0)$ & & \\
\hline $\begin{array}{l}\text { Use of inade- } \\
\text { quate method }\end{array}$ & $8(20.0)$ & $21(19.0)$ & & \\
\hline \multicolumn{2}{|c|}{ Papanicolau's Iest } & & 0.015 & \\
\hline $\begin{array}{l}\text { Papanicolau } \\
\text { in validity }\end{array}$ & $36(85.0)$ & $80(63.2)$ & & 1.51 \\
\hline $\begin{array}{l}\text { Papanicolau } \\
\text { not valid }\end{array}$ & $2(5.0)$ & $32(25.6)$ & & \\
\hline Never made it & $4(10.0)$ & $14(11.2)$ & & $1^{(\mathrm{c})}$ \\
\hline \multicolumn{5}{|c|}{ Vaccination coverage } \\
\hline Anti-tetanic & $41(97.6)$ & $104(82.5)$ & 0.014 & 8.67 \\
\hline Hepatitis B & $34(81.0)$ & $71(56.3)$ & 0.004 & 3.29 \\
\hline Rubella & $29(69.0)$ & $65(51.6)$ & 0.048 & 2.09 \\
\hline \multicolumn{2}{|c|}{ Use of ferrous sulfate (days) } & & $<0.001$ & \\
\hline 90 & $11(26.2)$ & $23(18.3)$ & & 3.43 \\
\hline 60 to 89 & $10(23.8)$ & $0(0)$ & & \\
\hline$<60$ & $15(35.7)$ & $60(47.6)$ & & \\
\hline Never had it & $6(14.3)$ & $43(34.1)$ & & $1^{(\mathrm{d})}$ \\
\hline
\end{tabular}

(a) Odds Ratio. ${ }^{\text {(b) The chance of exclusive breastfeeding and non-exclusive bre- }}$ astfeeding occur was calculated having as reference value the 'non-breastfeeding,(c)The chance to have Papanicolau's test valid was calculated having as reference value 'never made it'.(d) The chance of using ferrous sulfate for 90 days was calculated having as reference value 'never had it'.

\section{Discussion}

Most of the puerperas of the two groups had more than seven pre-natal appointments which is one of the parameters to guarantee good perinatal results $^{(9)}$. The assistance to pre-natal is made by a trained health professional starting early and with, at least, seven appointments, it provides better results in the assistance to delivery ${ }^{(5)}$.

As to the type of delivery it is highlighted that the percentage found in the study is worrying, once besides being a lot superior to the recommended one, it overtakes the national average of $43.8 \%$ of cesareans. The proportion of cesareans recommended by the World Health Organization must correspond to approximately $15 \%$ of the total number of deliveries ${ }^{(3)}$. Women who were submitted to cesarean presented a higher chance of intercurrences in the puerperium.

The last national research of demography and the woman and child health reveal that the prevalence of children in exclusive maternal breastfeeding until the sixth month was $39.8 \%$ in Brazil. Later on, the $2^{\text {nd }}$ research of prevalence of maternal milk was made in the Brazilian capital cities and the Federal District, which observed an improvement in the prevalence of exclusive maternal breastfeeding until the sixth month of life with a percentage of $41 \%$ for $\mathrm{Brazil}^{(3,10)}$. The same research showed that the probability of the children with 90 days of life to be in exclusive maternal breastfeeding is $34.3 \%$ in Brazil, $34.6 \%$ in the southeastern region and $32 \%$ in Minas Gerais. The result of the intervention group of our study showed to be better than the national, regional and state results.

Despite the positive results in the intervention group, according to the evaluation of the maternal breastfeeding of the World Health Organization, the finding is considered reasonable for the exclusive maternal breastfeeding, once the percentage found, $42.9 \%$, is below the percentage which is considered good, that is above $50 \%{ }^{(3,10)}$.

Even if the stimulus to maternal breastfeeding is present in the practice of the nurses is still needed 
to go further in the promotion of breastfeeding. It is important to consider that besides the technical knowledge related to lactation the puerperas need to be heard as to the difficulties and easiness and they should receive support in an active manner.

All the puerperas of the intervention group were informed on maternal breastfeeding. Among the most frequent actions taken by the nursing team during puerperium, the stimulus to breastfeeding is highlighted ${ }^{(7)}$. In the control group, on the contrary, it was observed that $20(15.9 \%)$ of the control group did not receive any information. A similar result to the control group was found in a cross-sectional study made in the counties of Rio Grande do Sul, which showed that $18 \%$ of the mothers did not receive any information on maternal breastfeeding ${ }^{(11)}$.

Despite the cultural factors, opinion of family members and personal wish to interfere in the act of breastfeeding, it is also influenced by the orientations and adequate support received by the women in all the phases of life, going through childhood, adolescence and adult age, with a especial attention during pregnancy and puerperium.

As to the use of contraceptive method in the puerperium no significant statistical difference was identified among the puerperas of the intervention and control group. We found $16.8 \%$ of the puerperas without the use of contraceptive methods and 39\% with inadequate use. The adequate use of some contraceptive method, at this moment, is fundamental to avoid unexpected pregnancy with a short interval between deliveries ${ }^{(12)}$.

Besides the worry with the guarantee of the health of the woman and the welfare of her family, the family planning is a right of men and women which must be contemplated in the several phases of life, also in the puerperium and in the post-abortion period, aiming at the right of choice for the planning of the offspring ${ }^{(13)}$.

Besides the use of contraceptive methods suffering influence of the access to the health services, of the availability of the methods, of managerial and social cultural factors, the health professionals also have an important role in the family planning. But there is the lack of information of the puerperas on the adequate contraceptive methods and a lack in the role of the nurse as in advisor concerning those methods ${ }^{(12)}$.

It is necessary to remove bureaucracy of some actions before, during and after the choice of the contraceptive methods, standardize the groups of reproductive rights at the health unit, facilitate the access of the women to these groups, train the professionals for the actions of family planning, and increase the resolutions of the professionals of primary attention. This set of measures can avoid the prolonged waiting for the methods, prevent undesired pregnancy and, especially, avoid the number of morbidity/mortality in the gravid puerperal cycle.

We noticed that the adequate puerperal assistance improved the access of the women to Papanicolaou and increased the coverage of the exam in the intervention group, once it was observed that, while in the intervention group 20 puerperas (52.6\%) made the exam during puerperium, only 19 puerperas (17\%) of the control group were submitted to the exam in this period.

One third of the cases of cervical uterine cancer attack the women during the reproductive period and the chance to be diagnosed during the gravidic puerperal cycle increases, because this can be the only contact of the woman with the health service for the control appointments, especially in pre-natal $\operatorname{period}^{(14)}$.

The stimulus to a puerperal appointment offering Papanicolaou's test for the women who never had it or had this test outdated is an important strategy that can be adopted routinely by the health professionals in order to decrease the number of women, also in the reproductive period, who fall ill and die due to this neoplasia.

The supplementation of ferrous sulfate for 90 days, as preconized by the World Health Organization, was more significant in the intervention group 
compared to the control group.

The main reason for not using ferrous sulfate during puerperium in the control group was the absence of prescription by a health professional, reported by $53 \%$ (23) of the puerperas. Despite not having been the main cause reported in the intervention group, the lack of prescription was still reported by two (33.3\%) women who did not use the medicine. Some maternity wards have the prescription to medicine in the hospital discharge as a routine. But the professionals of primary health care must check, in the first contact with the puerperas, if the medication was prescribed, if it is being used and, especially, to highlight the importance of that for the health of the puerpera. In case it has not been recommended in the hospital discharge, the prescription of ferrous sulfate and the orientation for its use must be made as early as possible.

The lack of use due to other reasons such as 'discomfort after use' or 'it is not necessary' was present in the two groups. The occurrence of undesirable side effects such as nausea, vomit, diarrhea, intestinal constipation and abdominal pain and the longtime of the treatment are some factors which make the adhesion to the treatment difficult. Many women consider the adverse effects of the medicine more undesirable than the alterations caused by anemia itself ${ }^{(15)}$.

The use of the ferrous sulfate in puerperium is less frequent than in the pregnancy. It was proved in the study that some women did not use the medication for considering that, after the delivery, it is not important or necessary to keep the use. There is the belief that, during pregnancy, the health of the fetus depends exclusively on the health of the mother, that is, to use the medicine while the woman is pregnant would be a maternal obligation, and, in the puerperium, there would not be this commitment, once they believed that the health of the child after the delivery depends on other factors ${ }^{(15)}$.

The study revealed a greater coverage of the anti-tetanic, rubella and hepatitis $B$ vaccines in the group that received assistance through the proposed guideline. There was significant statistic difference for the coverage of the three vaccines, but the most expressive difference was for the vaccine against hepatitis B, followed by the anti-tetanic vaccine and, at last, for the rubella vaccine. The chance for the puerperas of the intervention group to be immunized in comparison to the ones of the control group was respectively higher for the anti-tetanic, hepatitis $\mathrm{B}$ and rubella vaccines.

Although it is below the national target, the coverage of the anti-tetanic vaccine in the intervention group (97.6\%) was higher than the one found in a national study made which reported $69 \%$ of women immunized against tetanus ${ }^{(3)}$. Using the puerperal period to immunize the woman against tetanus is inadequate and opportune behavior, in our country the loss of opportunity of vaccination during the appointments of the population with the health service is still common in our country, with consequent jeopardizing of the vaccine coverage and, especially, risk of disease and death caused by immuno-preventable diseases.

The scarcity of researches which emphasizes the assistance in the puerperium in the primary health care justifies the making of this research. The approach in the hospital puerperal assistance was observed in detriment of the assistance in primary health care $^{(1)}$.

In the international scenario we identified two studies of assistance of puerperas through the programs of visits or assistance by the nurse and midwives. One study in Australia ${ }^{(16)}$ which emphasizes the relation of the assistance in puerperium with the mental health of the women and another in the United States ${ }^{(17)}$ which approached the assistance in puerperium also with other variables such as maternal breastfeeding and the use of contraceptive methods.

\section{Conclusion}

The study highlighted the statistically 
significant results in six of the seven variables tested, confirming the feasibility of that guideline in the assistance of nursing in the puerperium. The guideline showed to be effective when increasing the chance of the puerperas exposed to it to be contemplated with actions of promotion and prevention of the health of the women, such as the use of ferrous sulfate for 90 days, making the Papanicolaou's test, immunization with the anti-tetanic, hepatitis B and rubella vaccines. Besides the promotion of health of the puerpera, we noticed benefits for the health of the child such as exclusive maternal breastfeeding.

We found significant result in most of the variables tested despite the impossibility of using a random design that guaranteed the selection of the sample and the random allocation of the puerperas in the intervention and control groups, thus avoiding the bias of selection.

Another possible restriction of the study can be related to the time of evaluation of the intervention which is only three months, once puerperium is a complex period which requires a longer time of assistance and its last phase, the remote puerperium, starts on the $42^{\text {nd }}$ day and prolongs until 12 months after delivery. But we highlight some positive aspects of the study such as the acceptance of the puerperas, once most of them attended the scheduled appointment and the adhesion of the nurses.

Even facing the positive points of the studies and the favorable results for most of the variables tested, we identified the faults in the guarantee of the sexual and reproductive rights through the reorganization of the services, availability of contraceptive methods at the health units, training of the health professionals and the awareness of the puerperas on the adequate use of the methods.

Advancement in the practices is essential such as the prescription and incentive of the use of ferrous sulfate and in actions nursing actions such as the support to maternal breastfeeding and immunization. Another worrying finding was the approach of the professionals valuing the health of the child in detriment of the health of the puerpera. The difficulty of access and the need to standardize assistance in the puerperal period was clear in the primary health care.

The access to adequate assistance in puerperium can minimize the rates or morbidity/ mortality in the gravidic puerperal cycle and the lack of this assistance should be considered a loss of opportunity and intervention. As a manner to optimize the service and avoid the loss of opportunity we suggest the strategy to use the attendance of the puerpera to the health service, with the purpose of taking the child for the appointment of childcare, and offer at the same time the assistance to the puerpera until the end of the remote puerperium. This strategy can solve the problem of access, providing the optimization of time of the team and of the puerpera and, especially, to allow a glance on the woman and child dyad.

Puerperium deserves a closer look by part of the public policymakers of health, managers, health professionals, community and scholars, the evidences on the importance of the assistance in the puerperium are clear as well as the need of a more qualified care in this period and the direct relation of the post-partum care with some indicates of mother child health.

Through this study, we identify the reduced number of researches on the assistance to puerperium in the national and international scenario, and the need of making quantitative researches which fill this gap in this area with focus in primary care; which confirm the efficacy of the nursing care in this period and stimulate the elaboration of strategies and tools which contribute to the nursing assistance.

We consider that the guideline applied in this study is an appropriate and low cost technology and we understand that its implantation can, in the future, have an impact in the reduction of the morbidity/ mortality of the women in puerperium, contribute to the work of the nurses in the health of the woman at the primary health care and consolidation of the puerperal assistance in the primary health care in Brazil. 


\section{Acknowledgments}

To the 21 nurses of the unit of primary health care of Juiz de Fora, MG, Brazil who contributed in the enforcement of the proposed guideline. To the 168 puerperas who accepted to participate in the study. To the research assistants Izabella Figueiredo, Luiza Pereira Abranches and Tamires Lourenço de Assis who contributed in the data collection. To Terezinha Costa and especially to the professors Luiz Claudio Ribeiro and Cristina Arreguy-Sena for their contributions.

\section{Collaborations}

Souza ABQ contributed for the conception of work, data collection, analysis, data interpretation and writing of the article. Fernandes BM contributed for the conception of work, analysis, data interpretation, writing of the article and final approval of the version to be published.

\section{References}

1. Vieira F, Bachion MM, Salge AKM, Munari DB. Diagnósticos de enfermagem da NANDA no período pós-parto imediato e tardio. Esc Anna Nery. 2010; 14(1):83-9.

2. Minasi JM, Barros AM, Souza CS, Pinheiro TM, Francioni FF, Kerber NPC. Obstetric profile and complications of puerper as assisted in home visits. Rev Rene. 2013; 14(4):757-64.

3. Ministério da Saúde (BR). Pesquisa Nacional de Demografia e Saúde da Criança e da Mulher PNDS 2006: dimensões do processo reprodutivo e da saúde da criança. Centro Brasileiro de Análise e Planejamento. Brasília: Ministério da Saúde; 2009.

4. Barbastefano OS, Vargens OM. Prevenção da mortalidade materna: desafio para o enfermeiro. Rev Bras Enferm. 2009; 62(2):278-82.

5. Ministério da Saúde (BR). Secretaria de Atenção à Saúde, Departamento de Atenção Básica. Atenção ao pré-natal de baixo risco. (Série A. Normas e Manuais Técnicos. Cadernos de Atenção Básica, ${ }^{\circ}$ 32). Brasília: Ministério da Saúde; 2012.

6. Amaral RFC, Souza T, Melo TAP, Ramos FRS. Itinerário terapêutico no cuidado mãe-filho: interfaces entre a cultura e biomedicina. Rev Rene. 2012; 13(1):85-93.

7. Oliveira JFB, Quirino GS, Rodrigues DP. Percepção das puérperas quanto aos cuidados prestados pela equipe de saúde no puerpério. Rev Rene. 2012; 13(1):74-84.

8. Guedes AM. Tipos de desenhos de investigação: experimentais, quase-experimentais e não experimentais. [Internet] 2012 [citado 2012 jun 25]. Disponível em: http://www. investigalog.com/investigacion/tipos-dedesenhos-de-investigacao-experimentais-quaseexperimentais-e-nao-experimentais/

9. Ministério da Saúde (BR). Índice de Desempenho do Sistema Único de Saúde- IDSUS. [Internet] 2012. [citado 2012 mar 15]. Disponível em: http://portal.saude.gov.br/portal/arquivos/pdf/ IDSU-06/03/12.pdf

10. Ministério da Saúde (BR). Secretaria de Atenção a Saúde. Departamento de Ações Programáticas e Estratégicas. II Pesquisa de Prevalência de Aleitamento Materno nas Capitais Brasileiras e Distrito Federal. Brasília: Ministério da Saúde; 2009.

11. Cruz SH, Germano JA, Tomasi E, Facchini LA, Piccini RX, Thumé E. Orientações sobre amamentação: a vantagem do Programa de Saúde da Família em municípios gaúchos. Rev Bras Epidemiol. 2010; 13(2):259-67.

12. Parreira BDM, Silva SR, Miranzi MAS. Intenção de uso de métodos anticoncepcionais entre puérperas de um hospital universitário. Rev Rene. 2011; 12(1):150-7.

13. Ministério da Saúde (BR). Secretaria de Atenção à Saúde. Saúde sexual e saúde reprodutiva. Brasília: Ministério da Saúde; 2009.

14. Gonçalves CV, Duarte G, Costa JSD, Quintana SM, Marcolin AC. Perdas de oportunidades na prevenção do câncer de colo uterino durante o prénatal. Cienc Saúde Coletiva. 2011; 16(5):2501-10. 
15. Carmo LSMP. A concentração de hemoglobina e o uso de suplementos de ferro durante a gravidez e o parto. Rev Enferm Herediana. 2012; 5(1):19-25.

16. Fisher JRW, Wynter K, Rowe HJ. Innovative psycho-educational program to prevent common postpartum mental disorders in primiparous women: a before and after controlled study. BMC Public Health. 2010; 10:432.

17. Tsai PJS, Nakashima L, Yamamoto J, Ngo L, Kaneshiro B. Postpartum follow-up rates before and after the postpartum follow-up iniciative at Queen Emma Clinic. Hawaii Med J.2011; 70(3):569. 